\title{
Improving pathways to primary health care among LGBTQ populations and health care providers: key findings from Nova Scotia, Canada
}

\author{
Jacqueline Gahagan $^{1 *}$ and Montse Subirana-Malaret ${ }^{1,2}$
}

\begin{abstract}
Background: This study explores the perceived barriers to primary health care as identified among a sample of Lesbian, Gay, Bisexual, Transgender, and Queer (LGBTQ) identified individuals and health care providers in Nova Scotia, Canada. These findings, based on a province-wide anonymous online survey, suggest that additional efforts are needed to improve pathways to primary health among LGBTQ populations and in deepening our understanding of how to advance the unique primary health needs of these populations.

Methods: Data were collected from the LGBTQ community through an online, closed-ended anonymous survey. Inclusion criteria for participation were self-identifying as LGBTQ, offering primary health care to LGBTQ patients, being able to understand English, being 16 years of age or older, and having lived in Nova Scotia for at least one year. A total of 283 LGBTQ respondents completed the online survey which included sociodemographic questions, perceptions of respondents' health status, and their primary health care experiences. In addition, a total of 109 health care providers completed the survey based on their experiences providing care in Nova Scotia, and in particular, their experiences and perceptions regarding LGBTQ access to primary health care and physician-patient interactions.

Results: Our results indicate that, in several key areas, the primary health care needs of LGBTQ populations in Nova Scotia are not being met and this may in turn contribute to their poor health outcomes across the life course.

Conclusion: A framework of intersectionality and health equity was used to interpret and analyze the survey data. The key findings indicate the need to continue improving pathways to primary health care among LGBTQ populations, specifically in relation to additional training and related supports for health care providers who work with these populations.
\end{abstract}

Keywords: LGBTQ, Primary Health, Health providers, Health system, Nova Scotia

\section{Background}

According to the WHO [1], primary health includes five key elements which are related to "reducing exclusion and social disparities in health (universal coverage reforms); organizing health services around people's needs and expectations (service delivery reforms); integrating health into all sectors (public policy reforms); pursuing

\footnotetext{
* Correspondence: Jacqueline.gahagan@dal.ca

${ }^{1}$ School of Health \& Human Performance, Health Promotion, Gender \& Health Promotion Studies Unit (GAHPS Unit), Healthy Populations Institute (HPI), Dalhousie University, 6230 South Street, Halifax, NS B3H 3J5, Canada Full list of author information is available at the end of the article
}

collaborative models of policy dialogue (leadership reforms); and increasing stakeholder participation". However, the issues of exclusion and disparities in relation to primary health can result in certain populations not availing themselves of health care [2-5]. This is particularly the case for Lesbian, Gay, Bisexual, Transgender and Queer (LGBTQ) populations whose unique health needs may not be considered in primary health where 'health' has been constituted historically through a cisnormative and heteronormative framework [6-8]. Moreover, this can impact on optimal health and well-being across the life course, particularly given that LGBTQ

(C) The Author(s). 2018 Open Access This article is distributed under the terms of the Creative Commons Attribution 4.0 International License (http://creativecommons.org/licenses/by/4.0/), which permits unrestricted use, distribution, and 
populations are less likely to access primary health care services for fear of discrimination and stigma $[4,9,10]$. In addition, recent research has shown that many practicing health care professionals and health care trainees are often lacking knowledge, comfort or cultural competence in addressing a variety of health issues facing LGBTQ populations [11-14]. Cultural competence is an important consideration in primary health care as it refers to a set of attitudes, behaviours and policies to work effectively in cross-cultural settings [15]. A lack of access to culturally competent primary health care systems and providers can result in increased costs to society, including reduced life expectancy, a lower quality of life, and a higher burden of acute and chronic illness among LGBTQ populations (e.g. cancer, HIV, CVD) [16-18]. Previous research has also attributed higher rates of chronic disease among LGBTQ populations to discrimination, minority stress, avoidance of health care providers and irregular access to health care services [19, 20]. Therefore, developing culturally competent primary health care approaches for LGBTQ patients has become a priority in many health research and clinical practice settings [4, 21]. Given this, our study explores the main health concerns and perceived pathways and barriers to primary health care for LGBTQ populations from the perspective of both a sample of LGBTQ community members and health care providers.

\section{Methods}

\section{Respondents}

Data were collected from LGBTQ communities in Nova Scotia, Canada, one of the largest provinces on the east coast of Canada with a population of just under 1 million, through an online, closed-ended, anonymous survey which was developed in consultation with a community advisory committee. Inclusion criteria consisted of self-identifying as LGBTQ and/or offering primary health care to LGBTQ patients, being able to understand English, being 16 years of age or older, and having lived in Nova Scotia for at least one year. A total of 392 participants completed the anonymous online survey, of which 283 participants self-identified as members of the LGBTQ communities and 109 self-identified as health care providers, of whom 53 self-identified as non-LGBTQ and 56 self-identified as LGBTQ. Data were managed, analyzed and descriptive statistics generated using SPSS Version $20^{\text {is }}$.

\section{Measures}

The online survey was developed collaboratively between the research team and the community advisory board following both the completion of a scoping review on the key factors impacting LGBTQ health, as well as community consultations in urban and rural Nova Scotia with community stakeholders. The resultant survey consisted of closed-ended questions related to sociodemographic factors, self-perceived health status, and health care experiences. The health care provider survey also included a section on their experiences and perceptions regarding LGBTQ population's access to health care and physician-patient interactions. The anonymous, online survey was completed electronically by selecting radio buttons, checking boxes, and typing in text, depending on the nature of the question.

\section{Procedures}

The survey was posted online using Opinio following approval by the Dalhousie University Research Ethics Board. The survey remained open for a total of six months.

\section{Results}

The key results are presented in the following sections, starting with LGBTQ respondents $(N=283)$, followed by health care providers who did not self-identify as LGBTQ $(N=53)$, and LGBTQ self-identified health care provider respondents $(N=56)$.

\section{LGBTQ populations' perspective Sample description}

Of the respondents who completed the survey, the mean age was 32 years. Respondents self-reported sexual orientation, gender identity/expression, employment status, education, and ethnicity are offered in Table 1.

\section{Self-rated health status}

The majority of respondents defined both their self-perceived physical and mental health statuses to be Good/Somewhat Healthy (a score of 4 out of 5). In addition, the majority of respondents indicated that their health status has remained approximately the same in the last year, and rated their own health literacy as very good.

\section{Relationship with the health care system}

The majority of respondents reported having undergone a routine check-up within the last 12 months, reported having a primary health care provider or family doctor, and reported being satisfied with them. However, the majority also reported being uncertain about the level of LGBTQ-friendliness of their family doctor, their knowledge and cultural competence about LGBTQ issues, and the inclusiveness of the health care system in Nova Scotia. Both positive and negative interactions are offered in Table 2. 
Table 1 Demographics

\begin{tabular}{|c|c|}
\hline Variables & Percent \\
\hline \multicolumn{2}{|l|}{ Sexual orientation ${ }^{a}$} \\
\hline Gay & 27.2 \\
\hline Lesbian & 25.8 \\
\hline Bisexual & 30.0 \\
\hline Queer & 38.5 \\
\hline Questioning & 3.5 \\
\hline Heterosexual & 2.8 \\
\hline Other options (mostly pansexual and asexual) & 13.8 \\
\hline \multicolumn{2}{|l|}{ Gender identity/expression } \\
\hline Cisgender female & 40.3 \\
\hline Cisgender male & 13.3 \\
\hline Transgender/transsexual male to female & 5.3 \\
\hline Transgender/transsexual female to male & 9.9 \\
\hline Two spirit & 3.2 \\
\hline Genderqueer/non binary (or otherwise gender variant) & 18.7 \\
\hline Other options (mostly gender fluid or intergender) & 9.3 \\
\hline \multicolumn{2}{|l|}{ Employment $^{\mathrm{a}}$} \\
\hline Full-time position & 41.3 \\
\hline Part-time position & 16.3 \\
\hline Unemployed & 12.7 \\
\hline Full-time student & 32.5 \\
\hline \multicolumn{2}{|l|}{ Religion or faith } \\
\hline Raised in Christianity & 55.8 \\
\hline Raised in other faiths & 10.6 \\
\hline Not raised in any religious beliefs & 33.6 \\
\hline \multicolumn{2}{|l|}{ Self reported ethnicity } \\
\hline White & 88.0 \\
\hline Mixed heritage & 5.3 \\
\hline Aboriginal & 1.8 \\
\hline Black & 1.1 \\
\hline Asian & 0.4 \\
\hline Not indicated & 0.4 \\
\hline
\end{tabular}

Table $\mathbf{2}$ Interactions with the health care system

\begin{tabular}{lll}
\hline & & Percent \\
\hline Positive interactions & & \\
At least one good experience & LGB & 66.2 \\
with the health care system & trans & 68.7 \\
Negative interactions & & \\
At least one bad experience & LGB & 36.4 \\
with the health care system & trans & 55.5 \\
\hline Interactions with the health care system & &
\end{tabular}

Perceived importance of health-related topics regarding one's own health

The key self-perceived health-related topics for LGBQ, and trans individuals are offered in Tables 3 and 4, from most to least important.

\section{Pathways to health}

Overall, the factors that were perceived to positively contribute to their health and well-being were similar for LGBQ and trans populations. These factors included: a) self-care, b) personal coping skills, c) self-esteem, d) safe and inclusive school or work environment, e) social support, f) access to LGBTQ-friendly/safe spaces, and g) community mental health resources.

\section{Non- LGBTQ self-identified health care providers' perspective Sample description}

A total of 53 surveys were completed by health care providers from across Nova Scotia who did not self-identify as LGBTQ but who offer care to LGBTQ community members. In addition to answering sociodemographic questions, respondents offered their experiences and perceptions regarding LGBTQ populations' access to health care and physician-patient interactions. Respondents' average length of experience as a health care professional was 14 years, and types of health care professionals are offered in Fig. 1.

Table 3 Perceived importance of health related topics regarding one's own health

Perceived importance of health related topics regarding one's own health

LGBQ individuals

Reproductive health and family planning

Sexual health

Problematic substance use (drugs and alcohol)

Access to harm reduction supplies

(clean syringes, pipes, filters, alcohol swabs, safe sharps deposit...)

Access to safer sex supplies (e.g. condoms, dental dams)

HIV/AIDS

Diabetes and obesity

Trans individuals

Sexual health

Transition services for trans individuals

Reproductive health and family planning for trans individuals

Positive body image, self-esteem and coping strategies

Anxiety/stress and other mental health concerns

Access to safer sex supplies (e.g. condoms, dental dams)

Supportive housing

Nutrition/healthy eating

Healthy aging 
Table 4 Sexual orientation/gender Identity of LGBTQ health care providers

\begin{tabular}{ll}
\hline Sexual orientation $^{\text {a }}$ & Percent \\
\hline Gay & 32.1 \\
Lesbian & 41.1 \\
Bisexual & 12.5 \\
Queer & 32.1 \\
Questioning & 3.6 \\
Heterosexual & 1.8 \\
Other options ("inclusive”) & 1.8 \\
Gender identity/expression & 37.5 \\
Cisgender female & 23.2 \\
Cisgender male & 5.4 \\
Transgender/transsexual female to male & 10.7 \\
Genderqueer/non binary (or otherwise gender variant) & 8.9 \\
Not to disclose & 10.7 \\
Other options & 3.6 \\
Not indicated &
\end{tabular}

Sexual orientation of health care providers who identify as LGBTQ

${ }^{\mathrm{a}}$ sum does not add up to $100 \%$ because respondents were allowed to select all that apply

bmostly "woman", "female" and "male" (which suggests that some participants did not know the meaning of the term cisgender)

The majority of the health care provider respondents reported working in hospitals, primary health centres and community health centres (see Fig. 2).

\section{Patient-provider interaction}

The majority of the health care providers who did not identify as LGBTQ reported feeling a certain degree of discomfort when having to address LGBTQ specific issues with their patients, such as access to transition services for trans patients or family planning/reproductive health specifically for LGBTQ populations. These issues also included mental health, domestic abuse and problematic drug use. Amongst those who regularly take sexual histories of patients, most do not usually screen for non-heterosexual sexual activity. When asked about the frequency by which patients openly discuss their gender identity/expression or sexual orientation, most of the health care providers indicated that this occurs 'sometimes'.

Many (41.5\%) of the health care providers who did not identify as LGBTQ believe that the health concerns of LGBTQ populations are 'similar' to, but not entirely the same as those found among heterosexual, cisgender populations. However, $34 \%$ stated that the health concerns of the two populations are 'completely different', and $13.2 \%$ think that they are 'the same'. The remainder reported being 'uncertain'.

\section{LGBTQ knowledge and cultural competence}

Only $9.4 \%$ of non-LGBTQ identified health care providers in our survey indicated that they felt 'very knowledgeable' about issues related to sexual orientation and sexual behavior, and $3.8 \%$ about issues related to gender identity/expression. Over half (54.7\%) of respondents reported having never received training for cultural competence in relation to LGBQ populations, and $60.4 \%$ reported having never received training for cultural competence regarding trans populations. Most of those who have received such training have done so while in-service, mostly in the form of conferences or workshops. Nearly half (49.1\%) reported believing that their health care environment is inclusive of LGBTQ patients, and $35.8 \%$ are uncertain about that. Over half $(58.5 \%)$ reported that their working environment is inclusive of LGBTQ staff, while $34 \%$ are uncertain about this issue.

More than $50 \%$ of the health care provider respondents who did not self-identify as LGBTQ identified the need for further education regarding LGBTQ populations (e.g. CME LGBTQ knowledge, communication skills, etc.) as very important to enhance health care services. In addition, $43.4 \%$ considered inclusive signs and posters to be very important, and $49.1 \%$ considered the language used in medical intake forms to very important.

Perceived importance of health-related topics in LGBTQ health The health-related topics perceived as most important by non-LGBTQ identified health care providers were: a) sexual health, b) reproductive health and family planning, c) transition services for trans individuals, d) anxiety/stress and other mental health issues, and e) HIV/AIDS.

\section{Health care providers who identify as LGBTQ Sample description}

We obtained a total of 56 completed surveys from health care providers in Nova Scotia who self-identify as L, G, $\mathrm{B}, \mathrm{T}$ or $\mathrm{Q}$ (LGBTQ). The mean age of these participants was 41 years, and their sexual orientation and gender identity/expression are offered in Respondents' average duration of experience as a health care professional was nine years, and their professional training is offered in Fig. 3.

Most health care respondents reported working in hospitals, community health centres and other health services (Fig. 4).

\section{Patient-provider interaction}

Most LGBTQ-identified health care providers reported feeling comfortable when having to address LGBTQ specific issues with their patients, with the exception of reproductive concerns for transgender patients, where there was wide variability in levels of comfort reported. These respondents also reported feeling comfortable when addressing issues concerning mental health, 

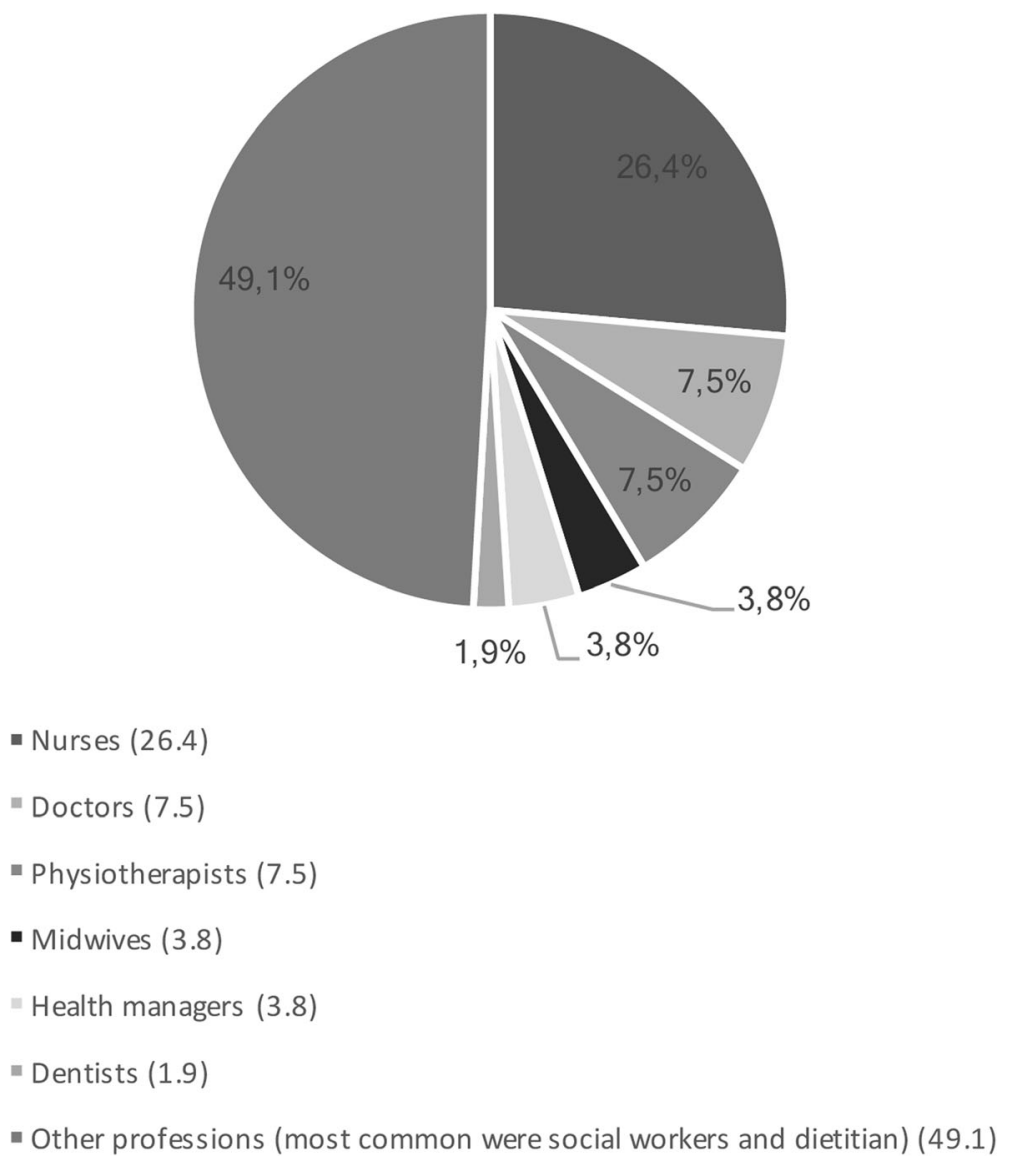

Fig. 1 Types of health professionals (Non-LGBT self identified care providers' perspective)

domestic abuse and problematic drug use. Amongst those who regularly take sexual histories of patients, most reported always or often screening for non-heterosexual activity. However, no differences were observed regarding the reported frequency with which patients openly discussed their gender identity/expression or sexual orientation with health care professionals.

Unlike what was observed among the non-LGBTQ identified health care provider respondents, the majority $(48.2 \%)$ of LGBTQ-identifying health care providers agreed that the health concerns of LGBTQ populations are different than the ones of heterosexual, gender-binary populations. Specifically, 33.9\% stated that they are similar, only $3.6 \%$ think that they are the same, and $8.9 \%$ reported being uncertain of what to think about this question.

\section{LGBTQ knowledge and cultural competence}

Over one quarter (28.6\%) of the LGBTQ-identified health care providers reported feeling very knowledgeable about issues related to sexual orientation and sexual behaviour, as opposed to $9.4 \%$ of those in the general group (non-LGBTQ), and 50\% feel somewhat knowledgeable. In addition, $17.9 \%$ reported feeling very knowledgeable about issues related to gender identity/ expression, versus $3.8 \%$ of the general group, and $42.9 \%$ reported feeling somewhat knowledgeable. The perception of not being knowledgeable enough is a more common response regarding trans patients than LGBQ patients. Just over half (53.6\%) of the sample reported not having received any training for cultural competence about LGBQ populations. In the same way, $67.9 \%$ had never received training for cultural competence about trans populations. Again, most of those who have been trained have received this education while in-service. Further, $46.4 \%$ of health care professionals reported that their health care environment is inclusive of LGBTQ patients, slightly less than their heterosexual counterparts; and $23.2 \%$ are uncertain about that, which means that professionals identifying as LGBTQ have more solid views on whether the health system is inclusive or not. Nearly 60\% (58.9\%) believed their working environment was inclusive of LGBTQ staff, while $26.8 \%$ remain uncertain; however, only $10 \%$ reported that their working environment was definitely not LGBTQ inclusive. 

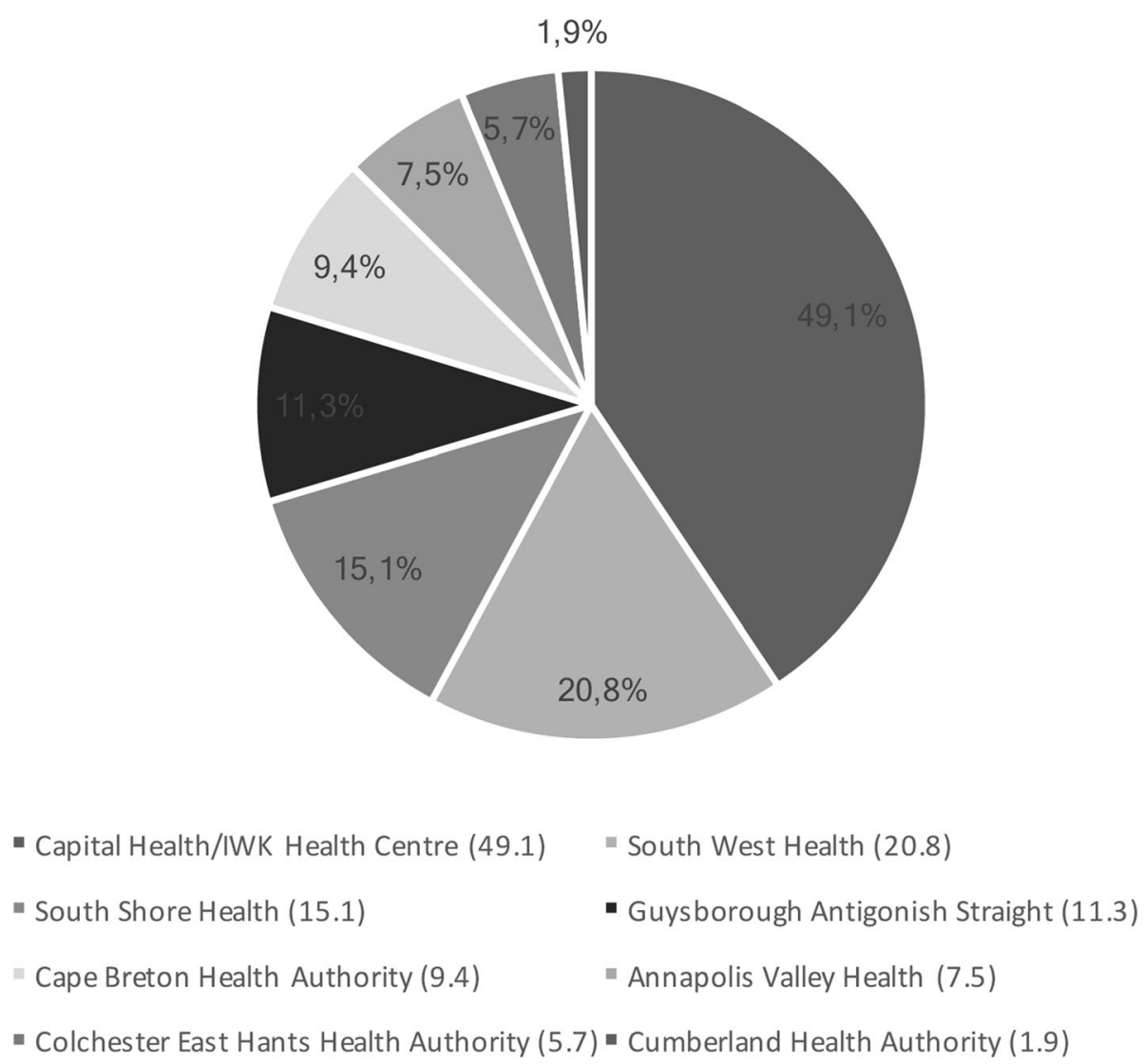

Fig. 2 Place of work (Non-LGBT self identified care providers' perspective)

Compared to the group analyzed in the previous section, health care providers considered the need for non-heterosexist medical intake forms as more important (55\%). Some professionals expressed the need for specific measures, such as gender-neutral bathrooms in health centers.

\section{Perceived importance of health-related topics in LGBTQ health} The health-related topics perceived as most important by LGBTQ-identifying health care providers were: a) anxiety/stress, b) depression, self-harm and suicidal ideation, c) positive body image, self-esteem and coping strategies, d) sexual health, and e) transition services for trans individuals.

In general, both subgroups of healthcare providers (LGBTQ-identifying and non) considered obesity, cancer screening and cardiovascular health amongst the least important health-related issues relative to others, despite the fact that approximately $40 \%$ of them consistently rate these topics as very important.

\section{Limitations}

It should be noted that closed-ended online surveys do have limitations, particularly where the questions are based on self-perceptions and hence subject to variable interpretation of the concepts used.

\section{Discussion}

The results of this online survey help bring to light a number of key issues related to improving pathways to LGBTQ primary health in Nova Scotia from the perspectives of both LGBTQ community members and health care providers. Specifically, it is noteworthy that more than one third of LGBQ respondents and more than half of trans respondents have had at least one poor experience with the health care system. Despite this, LGBTQ respondents rated their mental and physical health status as good overall, and most reported having a primary health care professional who they believe they can turn to for health matters.

In moving forward, it is important to note that there are key differences in the health-related topics perceived as most important for LGBQ versus trans individuals. Overall, these include reproductive health and family planning, sexual health, problematic substance use (e.g. drugs and alcohol), and access to harm reduction and safer sex supplies. In addition, trans individuals are also concerned with transition services, body image, self-esteem and coping strategies, and mental health issues, such as anxiety/ 


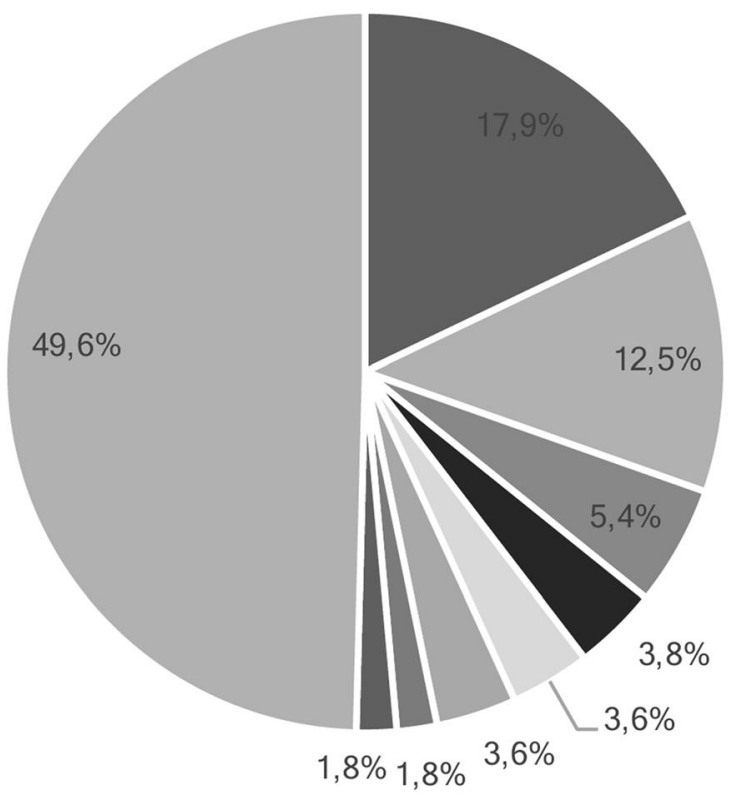

- Nurses (17.9)

- Medical doctors (12.5)

- Physiotherapists (5.4)

- Midwives (3.8)

" Health managers (3.6)

- Pharmacists (3.6)

- Psychologists (1.8)

- Health services coordinators $(1,8)$

" Other professions (most common being social worker and paramedic) (49.6)

Fig. 3 Types of health professionals (Health care providers who identify as LGBTQ)

stress, depression, or self-harm. Supportive housing, nutrition/healthy eating and healthy aging are also perceived as important for trans individuals.

Factors that were seen to positively contribute to overall health and wellness are very similar for LGBQ and trans populations and include self-care, personal coping skills, self-esteem, a safe and inclusive school or work environment, social support, access to LGBTQ-friendly/ safe spaces, and community mental health resources. Given that health concerns and priorities typically vary along the life course [16] it is important to view our study results from a life course perspective, which recognizes that social, cultural, and economic contexts shape experiences of health [22]. Many of the health issues highlighted in our survey represent a life course approach in understanding for example, issues related to sexually transmitted diseases, drug-consumption habits, dietary patterns, or pregnancy/fertility which are typically more relevant for people at early stages of adulthood, while the majority of cancers and cardiovascular or metabolic diseases typically present in later stages. Clinical guidelines recommend screening practices on the basis of risk, which implies that such practices are usually targeted towards particular subpopulations in which their effect can be more beneficial. The relatively young mean age of our sample may have had an influence on the perceived importance given by participants to different health-related topics.

From a health care providers' perspective, it is noteworthy that the perceived health related concerns of their LGBTQ patients do not always fully coincide with those expressed by LGBTQ individuals themselves. Specifically, many health care providers do not feel knowledgeable, comfortable or culturally competent 


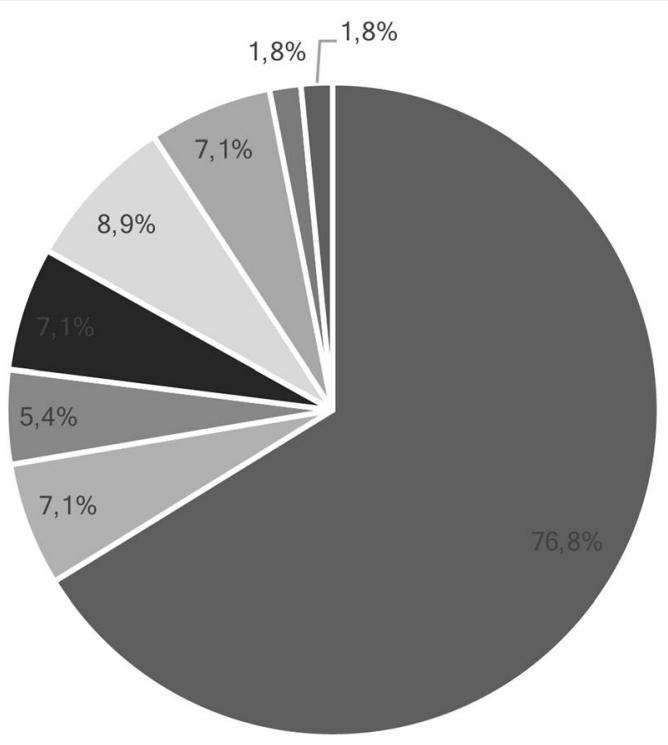

$$
\begin{aligned}
& \text { - Capital Health/IWK Health Centre (76.8) " South West Health (7.1) } \\
& \text { - Guysborough Antigonish Straight (7.1) " Cape Breton Health Authority (8.9) " Annapolis Valley Health (7.1) } \\
& \text { - Cumberland Health Authority (1.8) } \quad \text { " Pictou County Health Authority (1.8) }
\end{aligned}
$$

Fig. 4 Place of work (Health care providers who identify as LGBTQ)

enough when it comes to LGBTQ populations and their primary health care needs and this may be related to the lack of formal training on these issues in their medical education or in available Continuing Medical Education (CME) [23] training. There are differences between the comfort, perceptions of knowledge, and perceptions of LGBTQ inclusiveness of health services - both for patients and for professionals - between health care providers, regardless of their sexual orientation. However, even those identifying as LGBTQ expressed the need for additional training.

\section{Conclusion}

In general, respondents pointed to a variety of health-related issues that are of an intersectional and health equity nature [24, 25]. An intersectional and health equity approach points out the importance of the overlapping and intersecting axes of oppression such as gender, race, age, class and sexuality [26, 27].Our findings suggest that pathways to primary health for LGBTQ populations may be improved by addressing issues at the micro level of the individual (e.g. additional training and awareness) as well as at the macro systems level (e.g. health care systems, processes and procedures). Additional research in meeting the unique primary health needs of LGBTQ populations and health care providers is warranted, particularly given the complex and evolving interplay between micro and marco level factors that can collectively and synergistically impact on health outcomes among more socially marginalized populations. Our findings highlight the need to continue working towards the development of a truly welcoming, health equity focused, inclusive and culturally competent primary health system for all Nova Scotians, including LGBTQ populations.

\section{Availability of data and materials}

The data that support the findings of this study are available from Dalhousie University but restrictions apply to the availability of these data, which were used under license for the current study, and so are not publicly available. Data are, however, available from the authors upon reasonable request and with permission of Dalhousie University.

\section{Authors' contributions}

JG Substantial contributions to the conception or design of the work; or the acquisition, analysis, or interpretation of data for the work. Drafting the work or revising it critically for important intellectual content. Final approval of the version to be published. Agreement to be accountable for all aspects of the work in ensuring that questions related to the accuracy or integrity of any part of the work are appropriately investigated and resolved. MSM Substantial contributions to the conception or design of the work; or the acquisition, analysis, or interpretation of data for the work. Drafting the work or revising it critically for important intellectual content. Has participated sufficiently in the work to take public responsibility for appropriate portions of the content. Agreement to be accountable for all aspects of the work in ensuring that questions related to the accuracy or integrity of any part of the work are appropriately investigated and resolved. Both authors read and approved the final manuscript.

Ethics approval and consent to participate

This study has been conducted under the approval of Dalhousie University Research Ethics Board. 


\section{Competing interests}

The authors declare that they have no competing interests.

\section{Publisher's Note}

Springer Nature remains neutral with regard to jurisdictional claims in published maps and institutional affiliations.

\section{Author details}

'School of Health \& Human Performance, Health Promotion, Gender \& Health Promotion Studies Unit (GAHPS Unit), Healthy Populations Institute (HPI), Dalhousie University, 6230 South Street, Halifax, NS B3H 3J5, Canada. ${ }^{2}$ Advanced Studies Group on Violence, Clinical Psychology and Psychobiology Unit, Universitat de Barcelona, Faculty of Psychology, Passeig de la Vall d'Hebron, 171, 08035 Barcelona, Spain.

Received: 15 November 2017 Accepted: 29 May 2018

Published online: 13 June 2018

\section{References}

1. World Health Organization. Primary Health Care. Geneva: World Health Organization. Available from: http://www.who.int/primary-health/en/. Accessed 9 Feb 2017.

2. Gahagan J, Colpitts E. Understanding and measuring LGBTQ pathways to health: a scoping review of strengths-based health promotion approaches in LGBTQ Health Research. J Homosex. 2016;64(1):95-121.

3. Gardner A, de Vries B, Mockus D. Aging out in the desert: disclosure, acceptance, and service use among midlife and older lesbians and gay men. J Homosex. 2014;61(1):129.

4. Meyer I, Ouellette S, Haile R, McFarlane T. "We'd be free": narratives of life without homophobia, racism, or sexism. Sex Res Soc Policy. 2011;8(3):204-14.

5. Röndahl G. Heteronormativity in health care education programs. Nurse Educ Today. 2011;31(4):345-9.

6. Bonvicini KA, Perlin MJ. The same but different: clinician-patien communication with gay and lesbian patients. Patient Educ Couns. 2003;51: $115-22$

7. Mayer KH, Bradford JB, Makadon HJ, Stall R, Goldhammer H, Landers S. Sexual and gender minority health: what we know and what needs to be done. Am J Public Health. 2008;98(6):989.

8. Mulé NJ, Ross LE, Deeprose B, Jackson BE, Daley A, Travers A, et al. Promoting LGBT health and wellbeing through inclusive policy development. Int J Equity Health. 2009;8:18.

9. Goins ES, Pye D. Check the box that best describes you: reflexively managing theory and praxis in LGBTQ health communication research. Health Commun. 2013;28(4):397-407.

10. Moody C, Smith N. Suicide protective factors among trans adults. Arch Sex Behav. 2013:42(5):739-52.

11. Bradford J, Reisner SL, Honnold JA, Xavier J. Experiences of transgenderrelated discrimination and implications for health: results from the Virginia transgender health initiative study. Am J Public Health. 2013;103(10):1820.

12. Colpitts E, Gahagan J. The utility of resilience as a conceptual framework for understanding and measuring LGBTQ health. Int J Equity Health. 2016;15:60.

13. Makadon HJ. Ending LGBT invisibility in health care: the first step in ensuring equitable care. Cleve Clin J Med. 2011;78(4):220.

14. Andermann A. Taking action on the social determinants of health in clinical practice: a framework for health professionals. CMAJ. 2016;188(17-18):E474

15. Isaacs M, Benjamin M. Towards a culturally competent system of care, volume II, programs which utilize culturally competent principles. Washington, D.C.: Georgetown University Child Development Center, CASSP Technical Assistance Center: 1991.

16. Berberet $\mathrm{H}$. Putting the pieces together for queer youth: a model of integrated assessment of need and program planning. Child Welfare. 2006; 85(2):361-84.

17. Brotman S, Ryan B, Cormier R. The health and social service needs of gay and lesbian elders and their families in Canada. Gerontologist. 2003;43(2): 192-202.

18. Cahill S, South K, Spade J. Outing age: Public policy issues affecting gay, lesbian, bisexual and transgender elders. Washington, DC: Policy Institute of the National Gay and Lesbian Task Force; 2000. Available from www. thetaskforce.org (Accessed 25 Jan 2017)

19. Baker K, Hughes, M. Sexual orientation and gender identity data collection in the behavioral risk factor surveillance system 2016. Available from https:// www.americanprogress.org/issues/lgbt/reports/2016/03/29/134182/sexualorientation-and-gender-identity-data-collection-in-the-behavioral-risk-factorsurveillance-system/ (Accessed 12 Oct 2016).

20. Smart L, Wegner DM. The hidden costs of stigma. In: Heatherton TF, Kleck RE, Hebl MR, Hull JG, editors. The social psychology of stigma. New York: Guilford Press; 2000. p. 220-42.

21. Jackson B, Canadian Rainbow HC, Canadian EL. Whose public health? An intersectional approach to sexual orientation, gender identity and the development of public health goals for Canada. Saskatoon. In: Sask.: Canadian rainbow health coalition; 2006.

22. World Health Organization. A life course approach to health. Geneva: World Health Organization; 2000. Available from: http://www.euro.who.int/en/healthtopics/Life-stages. Accessed 14 Feb 2017.

23. Vandergrift JL, Gray BM, Weng W. Do State Continuing Medical Education requirements for physicians improve clinical knowledge? Health Service Research. 2017; https://doi.org/10.1111/1475-6773.12697.

24. Hankivsky O, Christoffersen A. Intersectionality and the determinants of health: a Canadian perspective. Critical Public Health. 2008;18(3):271-83.

25. Reid C, Penderson A, Dupéré S. Addressing diversity and inequities in health promotion: the implications of intersectional theory. In: Rootman I, Dupéré S, Pederson A, O'Neill M, editors. Health promotion in Canada: critical perspectives on practice (3rd ed.). Toronto, Canada: Canadian scholars press; 2012. p. 54-66.

26. Crenshaw KW. Mapping the margins: intersectionality, identity politics, and violence against women of color. (women of color at the center: selections from the third National Conference on women of color and the law). Stanford Law Rev. 1991;43(6):1241-99.

27. Colpitts E, Gahagan J. "I feel like I am surviving the health care system": understanding LGBTQ health in Nova Scotia, Canada. BMC Public Health. 2016;16:1005.

\section{Ready to submit your research? Choose BMC and benefit from:}

- fast, convenient online submission

- thorough peer review by experienced researchers in your field

- rapid publication on acceptance

- support for research data, including large and complex data types

- gold Open Access which fosters wider collaboration and increased citations

- maximum visibility for your research: over $100 \mathrm{M}$ website views per year

At BMC, research is always in progress.

Learn more biomedcentral.com/submissions 